\title{
Отраслевые особенности реализации концессионных соглашений: анализ преимуществ и рисков ${ }^{1}$
}

\section{Татьяна Тищенко}

Российской академии народного хозяйства и государственной службы при Президенте РФ, Москва, Россия

\author{
Информация о статье \\ Поступила в редакичию: \\ 14.09.2020 \\ Принята \\ к опубликованию: \\ 09.11 .2020
}

УДК 338.28

JEL H40

Ключевые слова:

государство и бизнес, концессионные соглашения, инфраструктура, частные инвестиции

\section{Keywords:}

government and business, concession agreements, infrastructure, private investments

\begin{abstract}
Аннотация
В статье представлены результаты анализа условий кониессионных соглашений в сфере транспорта, ЖКХ, экологии и сочиальных услуг, на предмет наличия и полноты инструментов снижения рисков неисполнения обязательств партнеров, снятия ограничений для участия бизнеса, включая модели возвратности инвестиций. По результатам исследования определены механизмы, позволяющие снизить асимметрию преимуществ и рисков участников концессий.
\end{abstract}

Industrial Specifics of the Concession Agreements

Implementation: Benefits and Risks Analysis

Tatyana Tischenko

\section{Abstract}

This paper presents the research results on the structure and terms of the concession contracts between the public and private sectors in the field of transport, housing and utilities, ecology, education and healthcare. The main limiting factor for developing the Public - Private Partnership (PPP) for the public partner is the risk of the investors failure to fulfill the obligations to finance the projects, the main risk for the private partner is associated with low return on the investments. The feasibility of the project budget financing has been assessed. The typical structure of the concession agreements has been analyzed. The proposals have been made for developing credit, insurance and guarantee instruments to reduce the asymmetry of benefits and risks.

\footnotetext{
${ }^{1}$ Статья подготовлена в рамках выполнения научно-исследовательской работы государственного задания РАНХиГС

DOI: https://dx.doi.org/10.24866/2311-2271/2020-3/67-79
} 


\section{Введение}

Созданная за последние десятилетия институциональная основа для развития государственно-частного партнерства (далее - ГЧП) в России, существенно расширила возможности участия компаний реального сектора в реализации общественно-значимых проектов. Принятие федеральных законов о концессиях в 2005 г. и ГЧП в 2015 г., и ряда нормативно-правовых актов в отношении тарифной политики и платных дорог, позволило снизить риски неопределенности прав и обязанностей сторон, и легализовать механизмы, обеспечивающие возврат средств частного инвестора. Изменение в 2007 г. статуса Внешэкономбанка (далее - ВЭБ) как финансового института развития, решил ряд проблем с доступностью долгосрочных кредитов для финансирования проектов. Дальнейшее развитие гарантийных и страховых механизмов расширило участие банков в кредитовании частного сектора, в том числе за счет консолидации их ресурсов в рамках консорциумов, ${ }^{2}$ крупные банки стали выполнять еще и функции организатора финансирования и финансового консультанта. Совершенствование финансовых рыночных инструментов также оказало позитивное влияние на развитие государственночастного партнерства в России, поскольку частные компании, желающие участвовать в финансировании проектов, получили возможность привлекать средства на рынках. Тем не менее, ограничения, связанные с обеспечением обязательств, балансом преимуществ и рисков участников концессионных соглашений, специфические для отдельных отраслей, сохраняются.

В течение последнего десятилетия вопросы применения ГЧП в России неоднократно освещались в научных изданиях, в том числе и в работах, посвященных изучению рисков и ограничений для развития концессионных соглашений. Следует отметить статью обобщающую понятие распределения рисков и построения единой системы управления [1], и исследования по анализу отраслевых особенностей реализации ГЧП [2] и [3], однако, вопросы кроссотраслевых инструментов компенсации рисков неисполнения обязательств партнеров не исследовались.

Основная цель исследования заключалась в выявлении инструментов компенсации рисков неисполнения обязательств, и баланса преимуществ государства и частного бизнеса при реализации концессионных соглашений. Осуществлялась проверка основной гипотезы о наличие специфических отраслевых ограничений для развития концессий в России.

Основным преимуществом концессий для государства является возможность использования опыта и ресурсов частного сектора для создания и управления общественно-значимой инфраструктурой. Частный партнер получает выгоды от диверсификации бизнеса, и снижения затрат на согласование проектов. Разделение обязательств между сторонами и наличие инструментов, обеспечивающих их исполнение, снижает риски конфликтов интересов, что способствует успешной реализации проекта.

${ }^{2}$ В 2015 г. было объявлено о создании консорциума группы «Базовый элемент», РФПИ и сингапурской компании «Сhang Airports International», который по результатам торгов стал собственником международного аэропорта города Владивосток. В декабре 2019 г. подписано концессионное соглашение о строительстве 4-го пускового комплекса центральной кольцевой автодороги Московской области, который финансируется синдикатом в составе Газпромбанка, Сбербанка, Евразийского банка развития (ЕАБР) и ВЭБ.РФ в объеме 35,8 млрд руб. сроком на 17 лет. 
В ходе исследования проводилась оценка обоснованности бюджетного финансирования проекта. Опыт использования ГЧП в других странах, свидетельствует, что данный механизм взаимодействия, часто оказывается более дорогим, чем государственная закупка, и в ряде случаев, не способен обеспечить улучшение качества предоставляемых услуг, включая их эффективность, охват и влияние на развитие; другими словами не обеспечивают соотношение цены и качества, принимая во внимание долгосрочные финансовые последствия [4].

Кроме этого, анализировалась возможность использования альтернативных механизмов создания и управления инфраструктурой. В некоторых отраслях использование концессий может вступать в определенное противоречие с трактовкой государственно-частного партнерства Международного валютного фонда, как соглашения, в котором частный сектор предоставляет объекты инфраструктуры и соответствующие услуги, которые традиционно предоставляло государство [5].

\section{Материалы и методы исследования}

Предметом исследования является содержание концессионных соглашений, в частности условий, касающихся характеристик объекта концессии, прав и обязанностей сторон, источников финансирования, распределение рисков, разрешения споров, моделей возврата средств частного партнера. Для анализа выбраны проекты, признанные лучшими (премия Минздрава, премия РОСИНФРА и др.) и/или типичными для отрасли или региона. Использовались теоретические методы исследования, включая системный анализ, методы обобщения для выявления характерных для рассматриваемой отрасли условий концессионных соглашений, и классификации, позволяющий конкретизировать типовые преимущества и риски, модели возврата средств.

Источниками данных для исследования являются:

- официальные сайты органов власти, включая сайт Российской Федерации для размещения информации о проведении торгов ${ }^{3}$;

- аналитическая и статистическая информация, представленная на сайтах компаний (Газпромбанк, ВЭБ, Сбербанк) и экспертного сообщества, включая зарубежные источники, информационное агентство Инвестинфра, Ассоциация «Центр развития ГЧП»;

- сайты частных инвесторов.

\section{Результаты и обсуждение}

Транспортная инфраструктура. По данным портала государственных торгов общее количество состоявшихся закупок в транспортном секторе составило 15 лотов; объектами концессии являются аэропорт, участки железнодорожный путей, городской транспорт. Преобладающей формой концессий в данной сфере является проектирование, строительство и эксплуатация объектов инфраструктуры на срок до 30 лет.

Риски неисполнения обязательств компенсируются еще на стадии конкурсного отбора инвестора. Так, при выборе концессионера для строительст-

${ }^{3}$ 2010-2020 Официальный сайт Российской Федерации для размещения информации о проведении торгов. Available at: https://www.torgi.gov.ru/lotSearch1.html?bidKindId=6 (accessed 25.04.2020) 
ва и эксплуатации канатной транспортной системы с приводной станцией метро «Сходненская» в Москве, установлены требования к финансовой состоятельности частного инвестора, которая подтверждается одним из следующих документов: выписка по банковскому счету о наличие средств в объеме не менее 160 млн. руб., подтверждением банка о предоставлении кредита в объеме 2 млрд руб., справкой о балансовой стоимости активов не менее 500 млн. руб. Наличие «повышенных» требований к квалификации и финансовой состоятельности участников конкурса, при реализации инфраструктурных проектов ГЧП является международной практикой [6].

Условия концессии прописываются отдельно для инвестиционного и эксплуатационного этапа, что обусловлено технологическими сложностями проектов. На инвестиционном этапе частный партнер обязуется создать и/или провести реконструкцию объекта, публичный партнер компенсирует риски неисполнения обязательств концессионера путем предоставления инвестором безотзывной банковской гарантии, страхованием ответственности за нарушение обязательств, залогом прав по договору банковского вклада (депозита). Риски, связанные с нарушением сроков и стоимости всех работ, а также технологические, операционные, управленческие и финансовые, возлагаются на концессионера. Концессионные соглашения в транспортной отрасли являются, по сути, контактами жизненного цикла; аналогичные подходы используются и в международной практике [7].

Возврат средств частного инвестора обеспечивается за счет платежей с потребителей услуг, в том числе по регулируемым тарифам. Высокая капиталоемкость и длительные сроки окупаемости проектов транспортной инфраструктуры, являются основными ограничивающими факторами участия частного инвестора; данные риски частично компенсируются платежами из бюджета публичного партнера.

В проекте создания и эксплуатации аэропортового комплекса в Новом Уренгое (Ямало-Ненецкий АО), с планируемым объемом инвестиций более 7,0 млрд руб., публичный партнер принимает на себя часть расходов на создание и реконструкцию объекта и часть расходов концессионера по проведению капитального ремонта. Модель возврата инвестиций частного партнера при реализации проекта строительства и эксплуатации трамвайной сети в Санкт-Петербурге, с объемом инвестиций 25,9 млрд руб., кроме платежей с потребителей за оказания услуг, предусматривает эксплуатационный платеж, как частичную компенсация потерь от регулирования тарифов и расходов на создание и эксплуатацию объекта.

В проекте аэропортовой инфраструктуры частный инвестор выплачивает ежегодный платеж в размере не менее 5 \% от доходов, полученных при превышении прогнозируемого объема пассажиропотока. При эксплуатации канатной дороги частный инвестор также осуществляет платежи, в случае превышения фактических доходов от оказания услуг от плановых значений. В проекте трамвайной инфраструктуры превышение в любом периоде выручки концессионера от оказания услуг над размером эксплуатационного платежа, выплачиваемого концедентом, распределяется между концессионером и частным инвестором. Отмечается асимметрия преимуществ и рисков партнеров: риски окупаемости проекта вследствие не поступления доходов в запланированном про- 
ектом объеме возлагаются на концессионера, и не распространяются на концедента, в то время как последний получает часть доходов, получаемых концессионером от предоставления услуг при эксплуатации объекта.

К преимуществам концессий в транспортной инфраструктуре относительно других механизмов взаимодействия государства и бизнеса, можно отнести не столько снижение рисков увеличения сроков строительства, как наличие оператора, предоставляющего услуги. В отсутствие концессионного механизма, например, закупки, подрядчик не стимулирован на повышение качества строительства, в то время как для инвестора вопрос качества становится экономической категорией, поскольку в процессе эксплуатации инвестор может нести дополнительные расходы на обслуживание и ремонт объекта. Обосновано и частичное возмещение расходов на строительство объекта за счет бюджетного финансирования, и перераспределение сверхдоходов от эксплуатации. Основным ограничивающим фактором развития концессий в транспортной сфере является риск увеличения сроков окупаемости и снижения фактических доходов от плановых/прогнозных значениях при сокращении объемов предоставляемых услуг.

Жилищно-коммунальное хозяйство. По данным портала государственных торгов количество состоявшихся конкурсов в секторе производства, передачи и распределения электрической и тепловой энергии, и коммунальной инфраструктуры составляет 652 конкурса, в том числе 311 по предложениям инвесторов, а общее количество проектов в сфере жилищно-коммунального хозяйства достигает до $40 \%$ от всех заключенных соглашений. Привлекательность концессий в сфере коммунальных услуг обусловлена вступившими в 2013 г. поправками в законодательство по запрещению передачи в аренду объектов ЖКХ с высоким уровнем износа; таким образом, концессия стала основным механизмом взаимодействия муниципалитетов и частного бизнеса. В последующие годы приняты поправки, позволяющие включить в тариф 5\% «предпринимательской прибыли», наличие гарантированной тарифной формулы на весь срок концессии, обязанность возврата инвестиций при расторжении концессионного соглашения, и возможность передачи имущества муниципальных предприятий в концессию при наличие долговых обязательств.

Подавляющее большинство проектов реализуется на муниципальном уровне, как следствие, концедентами проекта являются администрации городских округов, городских и сельских поселений. Концессионное соглашение предусматривает строительство, реконструкцию, модернизацию и эксплуатацию имущества, находящегося в собственности муниципальных образований. При предоставлении обособленных объектов, средний срок концессионного соглашения составляет от 5 лет; сроки концессий по инфраструктурным комплексам увеличиваются до 30 лет и более.

Концессионное соглашение по реконструкции и эксплуатация коммунальной инфраструктура холодного водоснабжения в Волгограде, заключено на срок 30 лет. Риски неисполнения обязательств со стороны частного инвестора обеспечиваются путем предоставления безотзывной банковской гарантии в размере 200 млн. руб., что составляет $0,3 \%$ от объема инвестиций. В соглашении указаны существенные нарушения условий концессионных соглашений, однако, относящиеся к процедурным действиям, таким как на- 
рушение сроков подачи и согласования документов, передачи объекта соглашения и иного имущества, прекращение деятельности концессионера, но не указаны последствия нарушений инвестиционных обязательств. Как следствие, к концу 2019 г. концессионер инвестировал в развитие коммунальной инфраструктуры Волгограда 6,4 млрд руб. из планируемых 58 млрд. руб. ${ }^{4}$ В акте о результатах контроля за исполнением концессионного соглашения ${ }^{5}$ указано, что инвестор не исполнил ряд обязательств по проектированию, строительству и вводу новых объектов (из 31 объекта, запланированных к реализации в 2019 г. завершены 2 объекта), ссылаясь на неисполнение договоров с третьими лицами. Рассматриваемый проект стал лауреатом Национальной премии в сфере инфраструктуры «РОСИНФРА 2015» в номинации «Лучший проект ГЧП в сфере ЖКХ» ${ }^{6}$, однако, можно признать, что премия выдана исключительно за намерения сторон.

Модель возврата инвестиций частного партнера предусматривает платежи с потребителей за оказания услуг по регулируемым тарифам. В рассматриваемом соглашении включен пункт о обязанности концедента оказывать содействие концессионеру при установлении тарифов, полностью обеспечивающих его финансовые потребности. Последствиями такого «конформизма» является необоснованный рост стоимости услуг для потребителей: в 2019 г. стоимость коммунальных услуг для жителей города увеличилась на 4,1\%, и это предельный показатель, рекомендованный федеральным центром.

Эксперты Института проблем естественных монополий (ИПЕМ 2017 г.) отметили, что «во многом, именно благодаря масштабным инвестициям, предусмотренным концессионным соглашением, тарифы на тепло, на горячую и холодную воду, а также на водоотведение вырастут значительно выше установленного для региона предельного уровня. Более того, опережающий рост, вероятно, продолжится и в ближайшие годы» ${ }^{7}$.

Риски возвратности инвестиций при предоставлении коммунальных услуг, связаны не только с тарифами, но и с объемами предоставления и себестоимостью. Наделение концессионера статусом гарантирующей организации позволяет увеличить количество потребителей, но это не всегда приводит к росту выручки, и прибыли, которые позволили бы осуществлять инвестиции в необходимом объеме. По данным финансовой отчетности концессионера по рассматриваемому проекту, выручка по итогам 2019 г. составила 3,3 млрд руб. (рост на 7,5\% относительно предыдущего года), а прибыль от продаж 713,8 млн руб., ${ }^{8}$ однако, за вычетом процентных платежей и прочих

\footnotetext{
4 Волгоград концессионный: как две частные компании стали хозяйками города-героя. Available at: https://newizv.ru/article/general/30-12-2019/volgograd-kontsessionnyy-kak-dve-chastnye-kompanii-stali-hozyaykami-gorodageroya(accessed 17.06.2020)

5 Акт от 30 июля 2020 года о результатах контроля за исполнением концессионного соглашения от 08.06.2015 г., заключенного с ООО «Концессии водоснабжения» на объекты коммунальной инфраструктуры (централизованные системы холодного водоснабжения и водоотведения) на территории муниципального образования городского округа город-герой Волгоград за 2019 год. Available at: http://www.volgadmin.ru/d/branches/gkh/documents/Reports/(accessed 16.06.2020)

${ }_{7}^{6}$ Дайджест PPP.RU Available at: https://p3institute.ru/netcat_files/25/27/Avgust_2016.pdf(accessed 25.07.2020)

${ }^{7}$ Новости ИПЕМ - Электроэнергетика. Рост тарифов на ЖКУ: в 11 «городах-миллионниках» превышены предельные индексы по 5 основным услугам. 2017 г. Available at: http://ipem.ru/news/ipem/1301.html.(accessed 07.07.2020)

${ }^{8}$ Аудиторское заключение о годовой бухгалтерской (финансовой отчетности) общества с ограниченной ответственностью «Концессии водоснабжения» за 2019 год. Available at: https://investvoda.ru/wp-content/uploads/2020/08/\%D0\%90\%D0\%97$\%$ D0\%9A $\%$ D0\%BE\%D0\%BD $\%$ D1\%86\%D0\%B5\%D1\%81\%D1\%81\%D0\%B8\%D0\%B8-

$\% \mathrm{D} 0 \% \mathrm{~B} 2 \% \mathrm{D} 0 \% \mathrm{BE} \% \mathrm{D} 0 \% \mathrm{~B} 4 \% \mathrm{D} 0 \% \mathrm{BE} \% \mathrm{D} 1 \% 81 \% \mathrm{D} 0 \% \mathrm{BD} \% \mathrm{D} 0 \% \mathrm{~B} 0 \% \mathrm{D} 0 \% \mathrm{~B} 1 \% \mathrm{D} 0 \% \mathrm{~B} 6 \% \mathrm{D} 0 \% \mathrm{~B} 5 \% \mathrm{D} 0 \% \mathrm{BD} \% \mathrm{D} 0 \% \mathrm{~B} 8 \% \mathrm{D} 1 \% 8$ F-2019.docx.pdf (accessed 15.07.2020)
} 
расходов, прибыль до налогообложения сократилась до 101,0 млн руб., что, естественно, не соответствует возможностям инвестора обеспечить инвестиции в проект объеме 58,0 млрд руб.

Ситуацию можно охарактеризовать как «патовую»: концессионер не имеет возможности выполнить обязательства в полном объеме, однако, и расторжение концессионного соглашения по инициативе публичного партнеpa, не решит проблему возвратности инвестиций для нового концессионера. В отсутствие данных о количестве неисполняемых в срок инвестиционных обязательств частного партнера по реконструкции объектов ЖКХ, спрогнозировать перспективы развития концессионного механизма не представляется возможным, однако, именно частному инвестору данная ситуация выгодна, так как он получает гарантированный постоянный доход, и не несет ответственности за неисполнения инвестиционных обязательств (для аналогичных ситуаций используется оборот «снятие сливок»). Проблемы несостоятельности концессионера по исполнению инвестиционных обязательств могут решаться за счет платежей концедента, в таком случае преимущество использования концессии для реконструкции объектов ЖКХ не очевидно. Существует и другой возможный вариант, когда через некоторое время, состояние инфраструктуры, которая не обновляется в связи с отсутствием средств у частного инвестора, дойдет до критическо-низкого уровня, а повышение тарифов или платежей концедента не компенсируют расходы на реконструкцию. В этом случае, концессионер, «снявший сливки» на эксплуатации без затрат на инвестиции, имеет законные основания выйти из соглашения, а все проблемы будут снова решаться за счет бюджета.

Механизм концессии в сфере ЖКХ все больше вытесняет стандартные механизмы закупок, количество соглашений растет, а удельный объем частных инвестиций (на 1 соглашение) сокращается. Так, на основе концессии проводятся капитальные ремонты сетей, со стоимостью работ по каждому объекту от 100-200 тыс. руб. ежегодно. В отличие от закупок, механизм концессии в ЖКХ более «лоялен» к бизнесу с точки зрения последствий за неисполнения контрактов.

Экология. Потенциальный рост инвестиционных проектов в сфере утилизации твердых бытовых отходов (ТБО) обусловлен реализацией национального проекта «Экология», однако, эффективность использования концессий не всегда однозначна. Большинство проектов реализуется на региональном и муниципальном уровне. Концессионные соглашения предусматривают строительство и эксплуатацию новых полигонов на срок до 25 лет и более, реконструкцию, модернизацию и эксплуатацию действующих объектов переработки отходов на срок от 5 лет. Для осуществления деятельности по утилизации ТБО общепринятой практикой является наличие региональных операторов (РКО), которые заключают договора на вывоз и утилизацию мусора на основе регулируемых тарифов.

Концессионное соглашение по межмуниципальной системе коммунальной инфраструктуры переработки и утилизации ТБО в Челябинской области является примером проработанности конкурсной документации и кон- 
цессионного соглашения. ${ }^{9}$ Предполагаемый срок концессии составлял 25 лет с объемом частных инвестиций не менее 3 189,9 млн. руб. и не более 3 668,4 млн. руб. Установление предельных объемов расходов концессионера (минимального и максимального) снижает риски неисполнения обязательств частного инвестора, так как учитывают невозможность предусмотреть все обстоятельства влияющие на первоначально установленную стоимость контракта длительного периода времени. Сроки создания объектов были определены с учетом получения разрешительной документации от органов власти, например, не более 24 месяцев с момента выдачи разрешения на строительство, что снижает риски неисполнения обязательств концессионера от неуправляемым им обстоятельств/ факторов. Обеспечение исполнения обязательств частного партнера осуществлялось одним из следующих инструментов: предоставление безотзывной банковской гарантии; передача в залог прав концессионера по договору банковского вклада (депозита); осуществление страхования риска ответственности за нарушение обязательств по соглашению.

Возврат и обслуживание привлеченных инвестиций осуществляется за счет предоставления услуг потребителям по регулируемым тарифам, доходов от реализации вторичного сырья, и иных ресурсов. Объем плановой валовой выручки концессионера рассчитывается ежегодно, что позволяет компенсировать риски снижения объемов предоставляемых услуг по независимым от частного инвестора обстоятельствам, например, расторжение договора услуг с прекратившим свою деятельность крупным предприятием.

Можно отметить, что преимущества и риски партнеров симметричны относительно прав и обязанностей концедента и концессионера, в том числе, и за счет компенсация недополученных доходов частного инвестора.

При всей проработанности условий концессионного соглашения и проведения конкурса, по решению Управления Федеральной антимонопольной службы по Челябинской области ${ }^{10}$ конкурс был аннулирован по исковому заявлению в связи с тем, что в области не утверждена территориальная схема по обращению с отходами и отсутствует нормативная база, регулирующая деятельность регионального оператора по обращению с твердыми коммунальными отходами. В настоящее время, концессионное соглашение предусматривает эксплуатацию одного объекта - Магнитогорского кластера, с объемом инвестиций 1,3 млрд руб.

Примером асимметрии преимуществ и рисков является концессионное соглашение в отношении действующего полигона ТБО в муниципальном образовании Алексеевское (Республика Татарстан), в рамках которого предусматривается реконструкция и эксплуатация объекта на срок 5 лет с объемом частных инвестиций 5 млн. руб. Концессионер обязан осуществлять реализацию предоставляемых услуг по регулируемым ценам/тарифам и предоставлять потребителям льготы, концессионная плата не предусмотрена. Концессия в данном случае не преследует цели замещения бюджетных средств част-

\footnotetext{
9 Приложение 9 к Приказу Министерства экологии Челябинской области от 9 августа 2016 г. № 704. Available at: http://www.mineco174.ru/htmlpages/Show/OxranaokruzhayushhejsredyCHely/Obrashheniesotxodami/koncessionnoesoglashenieosozdan/ Konkursnayadokumentaciya (accessed 25.06.2020)

${ }^{10}$ Решение Управления Федеральной антимонопольной службы по Челябинской области от 22 сентября 2016 г. N 45 07/18.1/16. Available at: https://dokipedia.ru/document/5331374 (accessed 20.06.2020)
} 
ными инвестициями, объем последних несопоставимо ниже/ничтожен относительно объема бюджетных расходов данного муниципального образования на охрану окружающей среды, которые составили 1,1 млрд руб. в 2017 г. Концессию в рассматриваемом соглашении можно отнести к ГЧП условно; по факту, в результате реализации проекта произошло перераспределение денежных потоков, получаемых от предоставления услуг от одной частной компании к другой.

Социильная сфера. Концессионные соглашения по развитию социальной инфраструктуры имеют специфические условия для каждого конкретного объекта по видам работ, срокам, инструментам обеспечения обязательств и распределения рисков.

Объектом концессионного соглашения образовательного комплекса в Нижнем Новгороде является комплекс из 3-х зданий и центра дополнительного образования на срок 15 лет. Концессионер обязуется построить здания 3-х новых школ, строительство которых было уже запланировано муниципалитетом еще в 2016-2018 гг. в новых жилых микрорайонах, ${ }^{11}$ и инфраструктуру для дополнительного образования детей на территории детского лагеря. Финансирование строительства осуществляется за счет кредита Сбербанка с использованием коробочных решений, собственных средств инвестора и средств федерального и регионального бюджетов, выделяемых в рамках празднования 800-летия Нижнего Новгорода. Данный проект позиционируется Министерством просвещения как пример использования концессии для строительства образовательных учреждений. ${ }^{12}$ Однако, по характеру взаимоотношений государства и бизнеса концессия является заменой прямых контрактов на строительство школ, например, инвестиционных. Аналогичный механизм успешно используется в Перми путем заключения соглашения со строительной компанией, которые в рамках реализации проектов по комплексному освоению территорий, возводят и объекты образования; бюджет берет на себя часть расходов на строительство ${ }^{13}$.

Механизм концессии, в отличие от закупок, более лоялен к выбору поставщика; нет жестких требований к его опыту и квалификации. Предложение инвестора ООО «Первая концессионная компания «Просвещение» зарегистрировано на сайте государственных закупок 29.10. 2019 г., через 2,5 месяца после официального создания компании, с уставным капиталом 100 тыс. руб. ${ }^{14}$, которая предлагала реализовать проект стоимостью 6,1 млрд руб., и до этого не имеющая опыта работы в проектировании и строительстве подобных объектов. Использовалась также схема объединения отдельно расположенных объектов строительства, которая позволила увеличить объем инвестиций

\footnotetext{
${ }^{11}$ «Верхние Печеры», «Юг», и ЖК в Сормовском районе

12 Модель государственно-частного партнерства, используемая, в частности, при строительстве образовательного комплекса «Школа 800» на 4550 мест в Нижнем Новгороде, в перспективе может применяться при строительстве образовательных организаций других типов. Об этом заявил министр просвещения РФ Сергей Кравцов на видеоконференции, состоявшейся после церемонии закладки первого камня в основание новой школы. 4 июня 2020 года. Министерство просвещения. Available at: https://edu.gov.ru/press/2556/mehanizmy-gosudarstvenno-chastnogo-partnerstva-usilivayutdostupnost-kachestvennoy-obrazovatelnoy-sredy/(accessed 10.06.2020)

${ }^{13}$ Сайт губернатора и Правительства Пермского края. 9 июня 2019 г. Available at: https://www.permkrai.ru/news/eshcheodin-zastroyshchik-postroit-i-peredast-v-sobstvennost-permi-detskiy-sad/(accessed 15.06.2020)

${ }^{14}$ Согласно данным СБИС, ООО «Первая Концессионная Компания «Просвещение» действует с августа 2019 г., размер уставного капитала составляет 100 тыс. руб., предложение инвестора зарегистрировано на сайте госторги 29.10.2019 г.
} 
и снизить конкуренцию среди участников конкурса; таким образом соглашение было заключено с инициатором.

Не предусмотрено и участие концессионера в предоставлении услуг, поскольку после строительства объекта частный инвестор предоставляет его в пользование образовательной организации. Таким образом, преимущества данного концессионного соглашения для публичного партнера и инвестора, ничтожны. Наибольшие выгода при фактическом отсутствие риска неплатежей получает кредитор, поскольку заемные средства будут возвращаться за счет регионального бюджета в течение 13 лет.

Концессионное соглашения по реконструкции нежилого помещения для оказания амбулаторной помощи в Ижевске заключено на срок 15 лет с планируемым объемом частных инвестиций 90,0 млн руб. Возврат средств осуществляется за счет платежей за оказание услуг по программе ОМС. По информации с портала государственных закупок, победителем открытого конкурса признано ООО «Премиум-Мед», однако, а настоящее время концессионером проекта является ООО Медицинские сервисные решения (ООО «МСР»). Проект стал в 2019 г. победителем в конкурсе Минздрава России в номинации «Лучший инфраструктурный проект на принципах ГЧП в здравоохранении», однако, экономическая целесообразность тиражирования данной модели сомнительна. Переданные в концессию нежилые помещения в реальности представляют собой действующее отделение гемодиализа ГКБ №6, площадью 540 кв. м., реконструкция позволило увеличить численность обсуживаемых на 15 чел. Следует отметить несоразмерность преимуществ и рисков данного проекта. Передача действующего отделения гемодиализа в концессию привела к перераспределению денежных потоков от государственного учреждения в частный сектор. До заключения концессионного соглашения ежегодная выручка компании не превышала 840 тыс. руб., а прибыль до налогообложения имела отрицательное значение. В качестве концессионера доходы компании увеличились до 174,4 млн руб. ${ }^{15}$, а прибыль до налогообложения за 2 года деятельности составила 45 млн руб. Основная часть доходов получена за счет средств ОМС, которые ранее направлялись в бюджетное учреждение. Возможно также, что условия концессионного соглашения были изменены, так как вместо установленного объема инвестиций в 90 млн руб., в финансовой отчетности компании стоимость основных средств, в том числе, используемых для собственных нужд, составила всего 58,2 млн руб. в 2018 г., при этом, расходы консолидированного бюджета Удмуртской Республики на стационарную помощь составили 1,6 млрд руб.

Общая структура концессионных соглашений для всех рассматриваемых отраслей представлена на рис. 1.

\section{Выводы и заключение}

По результатам анализа концессионных соглашений сделаны выводы о наличие дисбаланса преимуществ и рисков, как для государства, так и частного партнера, что является основным ограничительным фактором для развития концессионного механизма в России. Общие и специфические для рассмотренных выше отраслей риски и преимущества представлены в табл. 1.

${ }^{15}$ Отчетность организации ООО «МСР» Available at: https://www.list-org.com/company/8161101/report (accessed 23.06.2020) 


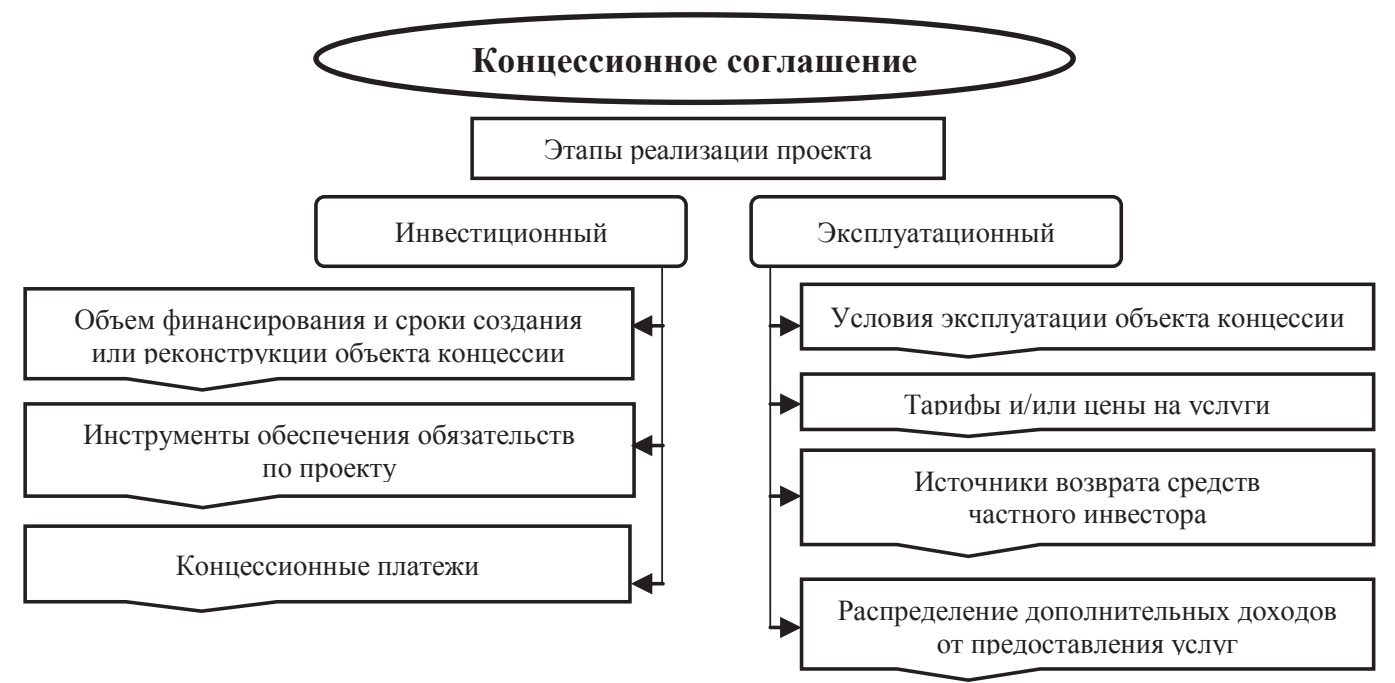

Puc. 1. Общая структура концессионных соглашений

Источник: составлено автором

В сфере транспорта, преимущества партнеров сбалансированы, однако, даже при участии публичного партнера в софинансировании объекта соглашения, частный партнер несет большую часть рисков, связанных с окупаемостью инвестиций, вследствие различных неуправляемых факторов снижения фактических доходов ниже плановых объемов (прекращение авиа и железнодорожного сообщения, наличия альтернативных маршрутов, изменение логистики компаний, пользующихся инфраструктурой).

Таблицуа 1

Отраслевая характеристика преимуществ и рисков реализации концессионных

\begin{tabular}{|c|c|c|c|c|}
\hline \multicolumn{5}{|c|}{ соглашений } \\
\hline \multirow{2}{*}{ Отрасль } & \multicolumn{2}{|c|}{ Публичный партнер } & \multicolumn{2}{|c|}{ Частный инвестор } \\
\hline & Преимущества & Риски/уровень & Преимушества & Риски и уровень \\
\hline $\begin{array}{l}\text { Транс- } \\
\text { портная } \\
\text { отрасль }\end{array}$ & $\begin{array}{l}\text { Снижение бюджет- } \\
\text { ных затрат на созда- } \\
\text { ние или реконструк- } \\
\text { цию объекта }\end{array}$ & \multirow{4}{*}{$\begin{array}{l}\text { Не исполнение } \\
\text { обязательств по } \\
\text { объемам и сро- } \\
\text { кам финансиро- } \\
\text { вания проекта. } \\
\text { Высокие для } \\
\text { капиталоемких } \\
\text { проектов. }\end{array}$} & \begin{tabular}{|l}
\multicolumn{2}{|l|}{ Софинансирова- } \\
ние проекта за \\
счет средств бюд- \\
жета
\end{tabular} & $\begin{array}{l}\text { Окупаемость проекта. } \\
\text { Высокий в зависимости от } \\
\text { объема инвестиций и сектора. }\end{array}$ \\
\hline ЖКХ & $\begin{array}{l}\text { Расходы финансиру- } \\
\text { ется за счет частного } \\
\text { инвестора }\end{array}$ & & $\begin{array}{l}\text { Гарантированный } \\
\text { доход }\end{array}$ & $\begin{array}{l}\text { Тарифные ограничения. } \\
\text { Средний в зависимости от } \\
\text { объема инвестиций }\end{array}$ \\
\hline Экология & $\begin{array}{l}\text { Расходы финансиру- } \\
\text { ется за счет частного } \\
\text { инвестора }\end{array}$ & & $\begin{array}{l}\text { Гарантированный } \\
\text { доход }\end{array}$ & $\begin{array}{l}\text { Tарифные ограничения. } \\
\text { Средний, в зависимости от } \\
\text { объема предоставленных услуг }\end{array}$ \\
\hline $\begin{array}{l}\text { Социаль- } \\
\text { ная сфера }\end{array}$ & $\begin{array}{l}\text { Снижение бюджет- } \\
\text { ных затрат на созда- } \\
\text { ние или реконструк- } \\
\text { цию объекта }\end{array}$ & & $\begin{array}{l}\text { Софинансирова- } \\
\text { ние проекта за } \\
\text { счет средств бюд- } \\
\text { жета. } \\
\text { Гарантированный } \\
\text { доход }\end{array}$ & $\begin{array}{l}\text { Низкая рентабельность инве- } \\
\text { стиций. } \\
\text { Тарифные и бюджетные огра- } \\
\text { ничения. } \\
\text { Средний, в зависимости от } \\
\text { объема } \\
\text { услуг. }\end{array}$ \\
\hline
\end{tabular}

Источник: составлено авторами

Преимущества и риски обеспечения обязательств по проектам по утилизации ТБО и в ЖКХ индивидуальны для каждого заключаемого соглаше- 
ния, однако, рассмотренное концессионное соглашение представляет собой типовую бизнес-модель взаимодействия, в отношении рисков неисполнения инвестиционных обязательств, и ограничений по возврату средств, связанных с тарифной политикой.

Рассмотренные концессионные соглашения в сфере здравоохранения и образования были признаны лучшими, однако, преимущества их реализации для государства не выявлены, поскольку средства бюджетов или внебюджетных фондов являются основными источниками доходов частного партнера.

Для снижения рисков неисполнения обязательств со стороны частного партнера предлагается расширить требования к финансовой обеспеченности концессионера. На стадии конкурсного отбора инвестора, представляется целесообразным включать требование предоставления выписки по банковскому счету о наличие средств в объеме не менее объема запланированных инвестиций в первые 6 месяцев реализации проекта16, или более с учетом объемов частных инвестиций и длительности проекта. Данное требование представляется значимым для соглашений по строительству объектов инфраструктуры в транспортной отрасли и в социальной сфере. Обеспечение обязательств по проектам реконструкции инфраструктуры в сфере ЖКХ и экологии, должно осуществляется за счет банковской гарантии предоставления кредита (кредитной линии) частному инвестору на весь объем инвестиций.

Представляется целесообразным включение в концессионные соглашения предельных объемов расходов концессионера (минимального и максимального), что снижает риски неисполнения обязательств частного инвестора, так как учитывают невозможность предусмотреть все обстоятельства, влияющие на первоначально установленную стоимость контракта длительного периода времени.

Для снижения рисков низкой окупаемости частных инвестиций, особенно в капиталоемких проектах создания объектов транспортной инфраструктуры, предлагается предусмотреть возможность компенсации за счет бюджета недополученных доходов от оказания услуг на стадии эксплуатации, и/или предоставления налоговых льгот.

Учитывая продолжительные сроки реализации концессионных соглашений (более 20 лет), которые, как правило, выходят далеко за пределы бюджетного планирования и стратегий развития компаний, необходимо внести в условия концессионных соглашений вопросы регулирования прав собственности, распределения полномочий по управлению объектом концессии, обеспечения обязательств по проекту в случае прекращения деятельности (например, лишение лицензии) или банкротства частного инвестора. В настоящее время в концессионных соглашениях такие условия и меры не предусмотрены.

\section{Сиисок источников / References}

1. Касаткина Б.П., Финоженкова Н.А. Концепция построения эффективной системы управления рисками проекта ГЧП. Вестник СПбГУПТД, 2019, № 3, сc. 5356. [Kasatkina B.P., Finozhenkova N.A. Koncepcija postroenija jeffektivnoj sistemy upravlenija riskami proekta GCP» [Kasatkina B.P., Finozhenkova N.A. Concept of

${ }^{16}$ Срок установлен с учетом поиска альтернативных источников финансирования проекта, в том числе за счет бюджетных средств публичного партнера с учетом возможного внесения изменений в закон о бюджете. 
building an effective risk management system of PPP project.] Vestnik SPbGUPTD =Bulletin of SPbGUPTD, 2019, no 3, pp. 53-56].

2. Гафурова Г.И. Концессия как метод привлечения частных инвестиций в ЖКХ. Ученые записки Российской Академии предпринимательства. 2013. № 4. сс. 146155. [Gafurova G.I. Kontsessiya kak metod privlecheniya chastnykh investitsii v $\mathrm{ZhKKh}$. [Gafurova G.I. Concession as a method of attracting private investment in housing and communal services]. Uchenye zapiski Rossiiskoi Akademii predprinimatel'stva $=$ Scientific notes of the Russian Academy of Entrepreneurship.2013, no 4, pp 146-155].

3. Гайнутдинов. Г.Р. Риски социальных проектов ГЧП на инвестиционной стадии. Экономика и предпринимательство. 2019, № 5, сc.620-622. [Gainutdinov. G.R. Riski sotsial'nykh proektov GChP na investitsionnoi stadii. [Gaynutdinov. G.R. Risks of social PPP projects at the investment stage] Ekonomika i predprinimatel'stvo = Economics and entrepreneurship, 2019, no.5, pp.620-622].

4. Jomo KS, Anis Chowdhury, Krishnan Sharma, Daniel Platz. Public-Private Partnerships and the 2030 Agenda for Sustainable Development: Fit for purpose? 2016, February. Available at: https://www.un.org/esa/desa/papers/2016/wp148_2016.pdf (accessed 20.08.2020).

5. Hemming R. Public-Private Partnerships», International Monetary Fund, Fiscal Affairs Department, Paper presented at the high-level seminar «Realizing the Potential for Profitable Investment in Africa». Organized by the IMF Institute and the Joint Africa». Available at: https://www.imf.org/external/np/seminars/eng/2006/rppia/pdf/hemmin.pdf (accessed 20.08.2020).

6. The Deutsche Gesellschaft für Internationale Zusammenarbeit (GIZ) GmbH. Report on the procurement of goods and services and the conclusion of financing agreement. 2006, February 28 - March 1. Available at: https://www.giz.de/en/downloads/giz2017-enreport-on-procurement-2016.pdf (accessed 20.08.2020).

7. Janice Weingart Brown, Robert Pieplow, Roger Driskell, Stephen Gaj, Michael J. Garvin, Dusty Holcombe, Michael Saunders, Jeff Seiders, Jr., Art Smith. Public-Private Partnerships for Highway Infrastructure: Capitalizing on International Experience. 2009, March. Available at: https://international.fhwa.dot.gov/pubs/p109010/pl09010.pdf (accessed 10.07.2020).

\section{Сведения об авторе / About author}

Тищенко Татьяна Владимировна, кандидат экономических наук, старший научный сотрудник, лаборатория исследований бюджетной политики, Российская академия народного хозяйства и государственной службы при Президенте РФ. 119571 Россия, Москва, проспект Вернадского, д. 82, кор.9, каб. 2205.E-mail: tishchenko-tv@ranepa.ru

Tatyana V. Tischenko, Candidate of Economic Sciences, Senior Researcher, Laboratory of Research Budget Policy Russian Presidential Academy of National Economy and Public Administrational. Of. 2205, Bldg. 9, 82 Prospekt Vernadskogo, Moscow, Russia 119571.E-mail: tishchenko-tv@ranepa.ru 